in train only two years ago by Máire Geoghegan-Quinn — who will depart as research commissioner of the European Union (EU) this autumn - was always as fanciful as it was beside the point.

That is because the ERA is a process, not an event. The project will never end. Anyone who imagines that it might do so only has to look at the United States. There, despite a genuinely single market and decades of federal incentives, huge disparities persist in 'research excellence' - however it is measured - between, say, Massachusetts and Montana.

That the problem is difficult does not mean that it should not be addressed. Optimists will note the remarkable progress that has been made in European research collaboration over the past 50 years and, in particular, over the past 15 . Huge EU research programmes have forged active collaboration involving tens of thousands of scientists. Academic mobility between nation states is visibly increasing, everywhere you look.

Almost all major facilities are now planned on the basis of panEuropean collaboration. Earlier this month, ground was broken on the latest of these: the European Spallation Source near Lund in Sweden, paid for by 17 European nations. (It is worth noting that the United States has not managed to start work on a billion-dollar-scale research facility for more than a decade.)

Most importantly, a cohesiveness and mutual understanding has emerged between senior European scientists that most parts of the world can only look upon with envy. Compared with the situation in east Asia in particular, the level of everyday dialogue and collaboration that exists in Europe in several major disciplines, such as particle physics and molecular biology, is singularly impressive.

This process had been going on for decades, before the formal concept of the ERA was endorsed by EU heads of state at a summit meeting in Lisbon in 2000.

The idea of taking specific administrative steps to improve researcher mobility was mainly theoretical at first, but has steadily gained impetus. And the decision was taken in 2012 for the European Commission to report annually on ERA progress, with the aim of cajoling more action out of member states.

At the same time, the political context for the ERA initiative has

changed for the worse. The ERA was conceived when the EU had just experienced a period of rapid convergence - in particular, economic convergence between living standards in the north and south.

Since 2008, however, the health of Europe's national economies has been diverging. Today, in research and innovation, as in other spheres, the wealthier regions are moving rapidly ahead, with the poorer ones falling behind. On the face of it, this makes

"With the rapid growth of the Internet, genuine global research collaboration has become almost routine." the ERA's objectives more elusive than ever.

Perhaps with this in mind, the commission's latest progress report pulls some of its punches. Earlier talk of 'naming and shaming' those member states that are slowest to implement ERA actions has been reined in.

These actions include steps to improve the portability of researchers' pensions and to address the gender gap in research. Women now obtain around half of Europe's PhDs, but will receive less than a quarter of this year's grants from the prestigious European Research Council. This is a major problem that both universities and research agencies prefer to overlook; its vigorous pursuit is a worthwhile goal for the commission.

Another change that has intruded on the ERA since 2000 is the accelerated emergence of a de facto global research area among elite researchers in most disciplines. Since 2000, with the rapid growth of the Internet, genuine global research collaboration has become almost routine, rendering 'local' collaboration less significant.

Still, Geoghegan-Quinn's successor as research commissioner — the current nominee is Portugal's Carlos Moedas - should pursue the goals of the ERA with as much vigour as possible. There will doubtless be renewed debate in the new European Parliament about the need for a fresh EU directive to force member states' hands over the ERA. In the meantime, it is up to the member states and their institutions to do more.

The 2014 deadline may be about to pass, but the project must endure. Ultimately, its fate rests in the hands of every department, institution and research agency in Europe - to build the ERA, one step at a time.

\section{Amped-up plants}

Bacterial enzyme supercharges photosynthesis, promising increased yields for crops.

\section{$\mathrm{T}$} he catalytic conversion of carbon dioxide and water to sugar and oxygen is arguably the most important chemical reaction in the world, and one of the oldest. It is so old, in fact, that it evolved when the world's atmosphere was much lower in oxygen than it is today. So, in a way, photosynthesis is its own worst enemy. Thousands of millions of years later, most modern plants struggle to photosynthesize because of all the darned oxygen in the air - oxygen that they helped to put there. These plants simply cannot distinguish between molecules of carbon dioxide and molecules of oxygen, so they waste their time and energy grabbing both.

Some plants can do better - for example, plenty of weeds (ever wondered why they grow so fast?) have evolved ways to concentrate carbon dioxide inside their leaves, to supercharge their photosynthesis. Cyanobacteria can do this too. But the majority of plants, including most of the crops we rely on for food, have developed a blunter strategy: produce lots and lots of the enzyme that drives the reaction. That enzyme, Rubisco, is thus among the most abundant proteins on the planet.

A significant amount of Rubisco still wastes its time grabbing useless oxygen - reducing the overall efficiency of global photosynthesis by almost one-third. When they discuss ways to boost the world's food supplies, plenty of plant scientists see leaves' wasted photosynthesis capacity as, well, low-hanging fruit.

What if crops could borrow the faster-acting Rubisco system of weeds and cyanobacteria? In theory, this would dramatically boost their growth rate and so their yield, all without needing any extra farmland. The appeal of such a strategy is obvious, particularly in the face of the often-quoted United Nations demand for global food production to double by 2050 .

In practice, replacing the enzyme has proved difficult. But there is encouraging news: on Nature's website, researchers report that they have made tobacco plants that use the Rubisco from a cyanobacterium (M. T. Lin et al. Nature http://dx.doi.org/10.1038/nature13776; 2014). Sure enough, the transformed plants photosynthesize faster and have higher rates of $\mathrm{CO}_{2}$ turnover than their conventional counterparts. Faster-growing tobacco plants might not sound like a boon for global welfare, but they do demonstrate what might be possible in future. (Tobacco is a common model organism for genetic-engineering research.)

As biologists Dean Price and Susan Howitt write in an accompanying News \& Views (G. D. Price and S. M. Howitt Nature http://dx.doi. org/10.1038/nature13749;2014): "The work is a milestone on the road $\rightarrow$ NATURE.COM To comment online, click on Editorials at: go.nature.com/xhunqv to boosting plant efficiency. The advance can be likened to having a new engine block in place in a high-performance car engine - now we just need the turbocharger fitted and tuned." Available in any colour you like, as long as it's green. 